\title{
Quantification of major and trace elements in fluid inclusions and gas bubbles by laser ablation inductively coupled plasma mass spectrometry (LA-ICP-MS) with no internal standard: a new method
}

\author{
Anastassia Y. Borisova ${ }^{1,2}$, Stefano Salvi ${ }^{1}$, German Velasquez ${ }^{3}$, Guillaume Estrade $^{1}$, Aurelia Colin ${ }^{1}$, and \\ Sophie Gouy ${ }^{1}$ \\ ${ }^{1}$ Géosciences Environnement Toulouse, GET - UMR 5563 - OMP - CNRS - UT3 - CNES, \\ 14 Avenue E. Belin, 31400 Toulouse, France \\ ${ }^{2}$ Geological Department, Lomonosov Moscow State University, MSU, \\ Vorobievu Gori, 119991, Moscow, Russia \\ ${ }^{3}$ Instituto de Geología Económica Aplicada - GEA, Universidad de Concepción, Casilla 160-C Concepción, \\ Chile
}

Correspondence: Anastassia Y. Borisova (anastassia.borisova@get.omp.eu)

Received: 7 January 2021 - Revised: 19 April 2021 - Accepted: 23 April 2021 - Published: 2 June 2021

\begin{abstract}
Recent advances in laser ablation inductively coupled plasma mass spectrometry (LA-ICP-MS) open new perspectives for quantification of trace metals and metalloids in mineral-hosted fluid inclusions and glasshosted gas bubbles. This work is devoted to a new method applied to quantify element concentrations (at partsper-million and weight percent levels) in natural and synthetic fluid inclusions and gas bubbles by using only an external calibrator in cases where internal standardization is unavailable. For example, this method can be applied to calculate element (metal and metalloid) concentrations in carbonic $(\mathrm{C}-\mathrm{O}-\mathrm{H})$ fluid inclusions and bubbles. The method is devoted to measuring incompatible (with the host mineral and glass) trace elements originally dissolved into the trapped fluid. The method requires precise estimation of the fluid density, the inclusion/bubble volume or average radius, and measurement of the laser ablation crater radius by independent microanalytical techniques as well as accurate data on the concentration of major/minor elements compatible with the host mineral (or host glass). This method, applicable for analyses of hydrous carbonic fluid inclusions and gas bubbles hosted in silicate minerals and glasses, relies on the absence of a matrix effect between fluid, host mineral and daughter phases (silicate, oxide or sulfide) and the external calibrator (e.g., reference silicate glasses) during the LA-ICP-MS analysis, an assumption validated by the use of femtosecond lasers.
\end{abstract}

\section{Introduction}

Development of new methods for a "standardless" quantification of fluid composition is of utmost importance in geochemical research, particularly nowadays, given the continuous evolution of analytical facilities and the difficulties in providing reliable internal calibration. For example, Rickers et al. (2004) and Cauzid et al. (2006) have proposed a method for standardless quantification of major and trace element contents in fluid and melt inclusions based on synchrotron radiation-induced X-ray fluorescence. However, in situ techniques such as those provided by laser ablation inductively coupled plasma mass spectrometry (LA-ICP-MS) are much more readily available to geologists. Leach and Hieftje (2001) developed a method for standardless analysis of synthetic alloys by single-shot LA-ICP-MS, but this turned out to be only semiquantitative. To our knowledge, to this day there is no method allowing the standardless analysis of the fluid phase contained in fluid inclusions nor in gas bubbles commonly found as inclusions in glass. 
The traditional method used by the majority of researchers to quantify LA-ICP-MS analyses requires internal standardization (an internal calibrator) in order to produce an absolute measure of the elements contained in a fluid inclusion. Most commonly, fluid or melt inclusions contain either a saline fluid (commonly $\mathrm{NaCl}$ ) or a silicate component, respectively. In the latter case, the inclusion can be heated and quenched to a homogenous silicate glass which is measurable by an electron microprobe (e.g., Borisova et al., 2006, 2008, 2012; Vikentiev et al., 2012), although this is a long and complex process. In both cases, independent measures of the concentration of $\mathrm{Na}$ or other major elements $(\mathrm{Al}, \mathrm{Si}, \mathrm{Cl})$ are used for internal standardization to quantify the concentrations of the trace elements ( $<1000$ ppm) (e.g., Longerich et al., 1996; Schafer et al., 1999; Halter et al., 2002; Heinrich et al., 2003; Borisova et al., 2006, 2012; Pettke et al., 2012; Seo et al., 2011; Vikentiev et al., 2012). However, the trace element contents in other, less common but nonetheless important types of inclusions such as those containing pure gaseous $\mathrm{C}-\mathrm{O}-\mathrm{H}$ species as well as in gas bubbles in glasses and glass-inclusion-hosted bubbles (e.g., Kamenetsky et al., 2002; Lowenstern, 2015; Schiavi et al., 2020) have never been quantified for trace elements because of the infeasibility of internal standardization. As an example, Kamenetsky and Kamenetsky (2010) described $\mathrm{Cu}$ - and Ag-bearing $\mathrm{CO}_{2}$-rich bubbles in basaltic glasses from the Macquarie Island ophiolite but could not evaluate their trace element concentrations.

Recently, several attempts were made to estimate trace element contents in $\mathrm{NaCl}$-poor inclusions (or in gas bubbles) using LA-ICP-MS data by estimating a value for the internal calibrator. Hanley and Gladney (2011) described quartzhosted, Ni-, Cu-, Pd-, Bi-, Te- and Fe-bearing $\mathrm{CO}_{2}$-rich inclusions from the Roby zone, Lac des Iles Complex (Ontario, Canada), as containing only minor bulk NaCl $(0.1 \mathrm{wt} \%-$ 1 wt $\left.\% \mathrm{NaCl}_{\text {equiv }}\right)$. They suggested the $\mathrm{Na}$ contents in the inclusions and used these values as an internal calibrator to quantify the trace metals in the inclusions. Scambelluri et al. (2004) tried quantifying the trace element concentrations in $\mathrm{NaCl}$-poor carbonic fluid inclusions by using a bestguess value of $2 \mathrm{wt} \% \mathrm{NaCl}_{\text {equiv }}$ as the maximum fluid salinity. Spandler et al. (2007) attempted the same task by relaying on mass balance considerations. Ferrando et al. (2009) assumed a $\mathrm{Si}$ concentration and used it as an internal calibrator for inclusions from ultrahigh-pressure rocks of the Brossasco-Isasca Unit of the Southern Dora-Maira Massif without any further correction for the host mineral contribution to the bulk fluid inclusion signals. All of these attempts to apply guessed concentrations to fluid composition quantification only produced results plagued by likely high uncertainties (sometimes undiscussed and non-evaluated) and no means to assess them. To further increase the need for standardless quantification, it is now established that high concentrations of metals can be transported by pure carbonic fluids (e.g., CO- or $\mathrm{CO}_{2}$-bearing; Simakin et al., 2016, 2021). The high concentration of metals has been detected but not quantified in the produced CO-rich synthetic fluid inclusions and bubbles. Therefore, in order to quantify the trace element concentrations in natural and synthetic low- $\mathrm{NaCl}$ carbonic fluid inclusions and gas bubbles, where either no or only minor concentrations of internal standards for the LA-ICP-MS method are available, we have developed the method discussed below.

\section{Method}

\subsection{Quantification of element concentrations in fluid inclusions and gas bubbles}

The method that we propose builds on the consideration of element pairs: (i) a first element, termed $X$, which must be strongly compatible in the mineral hosting the fluid inclusion or gas bubble; a second element, termed $Y$, which is enriched in the fluid or vapor and must be strongly incompatible in the host mineral (host glass). The concentration of $X$ must be known, while that of $Y$ is unknown. All other elements investigated must belong either to the host-compatible $X$ group or to the host-incompatible $Y$ group, which represents the unknown elements contained in the fluid inclusion or gas bubble. (ii) The method assumes chemical homogeneity of the measured inclusion and of the host mineral in the investigated zone. (iii) An additional requirement is that, during LA-ICP-MS analysis, there are no or only small matrix effects interfering between the investigated fluid-mineral (or fluid-glass) pair and the external calibrator (e.g., reference silicate glass), both of which must be analyzed for the same isotopes under the same analytical conditions. That means that the isotopic sensitivities should be similar between the different matrices (fluid, silicate, oxide or sulfide, and silicate calibrator) with no matrix effect. These conditions can be obtained using femtosecond lasers for the ablation (Fernandez et al., 2007; Velasquez et al., 2012, 2018; Poitrasson and d'Abzac, 2017; and references therein) as they have been shown to overcome matrix effects, which occur regularly with nanosecond lasers. Indeed, the interaction between the laser-induced plasma and the end of the laser pulse no longer exists in the femtosecond laser ablation regime (Poitrasson and d'Abzac, 2017). As a result, the specific femtosecond laser-matter interaction has led to greatly reduced chemical fractionation effects, allowing application of matrix-independent calibration for both elemental and isotopic analysis. The next benefit of femtosecond laser ablation is the independence of the laser-matter interaction from the optical properties of the target. This makes it capable of fully controlled and efficient ablation of optically transparent materials like quartz and calcite (Poitrasson and d'Abzac, 2017). Nevertheless, the $193 \mathrm{~nm}$ ultraviolet nanosecond excimer laser has been demonstrated to produce small matrix effects between fluids, silicates, oxides and possibly sulfides 
(Horn et al., 2001; Heinrich et al., 2003), and as such it is an excellent alternative to femtosecond lasers.

The method implies that laser ablation sensitivities for elements $X$ and $Y$ in a reference material (i.e., external silicate glass calibrator such as the NIST standard reference material (SRM) series) are known, which can be expressed as

$S^{X / Y}=\frac{S^{X}}{S^{Y}}=\frac{\sum_{\mathrm{I}} X}{\sum_{\mathrm{I}} Y} \frac{C^{Y}}{C^{X}}$,

where $S^{X / Y}$ is a sensitivity factor; $S^{X}$ and $S^{Y}$ represent chosen isotope sensitivities (in counts per second per ppm, cps ppm ${ }^{-1}$ ); $\sum_{\mathrm{I}} X$ and $\sum_{\mathrm{I}} Y$ are integrated (backgroundsubtracted) LA-ICP-MS pattern intensities (cps) for a chosen isotope; and $C^{X}$ and $C^{Y}$ are the concentrations (ppm) of element $X$ and $Y$, respectively.

Considering an ablated host mineral (glass) zone where the fluid phase (gas bubble or fluid inclusion) is localized, the ratios of element concentrations are calculated according to the equation

$\frac{C_{\text {ablation }}^{Y}}{C_{\text {ablation }}^{X}}=\frac{S^{X}}{S^{Y}} \frac{\sum_{\mathrm{I}} Y}{\sum_{\mathrm{I}} X}=S^{X / Y} \frac{\sum_{\mathrm{I}} Y}{\sum_{\mathrm{I}} X}=S^{X / Y} k^{Y / X}$,

where $C_{\text {ablation }}^{X}$ and $C_{\text {ablation }}^{Y}$ are the concentrations of elements $X$ and $Y$ in parts per million in the ablated zone, respectively. The coefficient $k^{Y / X}=\frac{\sum_{\mathrm{I}} Y}{\sum_{\mathrm{I}} X}$ relates the background-subtracted integrated intensities $\sum_{\mathrm{I}} X$ and $\sum_{\mathrm{I}} Y$ (cps) for the selected isotopes in the ablated zone of the host mineral-fluid (glass-fluid) inclusion system.

The following assumptions must hold true:

$M_{\text {ablation }}^{X}=M_{\text {host }}^{X}$,

$M_{\text {ablation }}^{Y}=M_{\text {incl }}^{Y}$,

where $M_{\text {ablation }}^{X}$ and $M_{\text {ablation }}^{Y}$ are the masses ( $\mathrm{g}$ ) of elements $X$ and $Y$ in the ablated zone, and $M_{\text {host }}^{X}$ and $M_{\text {incl }}^{Y}$ are the masses of elements $X$ and $Y$ contained, respectively, in the ablated host mineral and in the ablated inclusion (Fig. 1). If we set $M_{\text {ablation }}$ equal to the total mass ( $\mathrm{g}$ ) of the ablated zone, i.e., the host mineral plus the inclusion, we can write

$C_{\text {ablation }}^{Y}=\frac{M_{\text {ablation }}^{Y}}{M_{\text {ablation }}}=\frac{M_{\text {incl }}^{Y}}{M_{\text {ablation }}}$,

$C_{\text {ablation }}^{X}=\frac{M_{\text {ablation }}^{X}}{M_{\text {ablation }}}=\frac{M_{\text {host }}^{X}}{M_{\text {ablation }}}$,

which, combined, result in

$\frac{C_{\text {ablation }}^{Y}}{C_{\text {ablation }}^{X}}=\frac{M_{\text {incl }}^{Y}}{M_{\text {host }}^{X}}$.

Recalling Eqs. (2) and (7) we can write

$\frac{C_{\text {ablation }}^{Y}}{C_{\text {ablation }}^{X}}=S^{X / Y} k^{Y / X}=\frac{M_{\text {incl }}^{Y}}{M_{\text {host }}^{X}}$

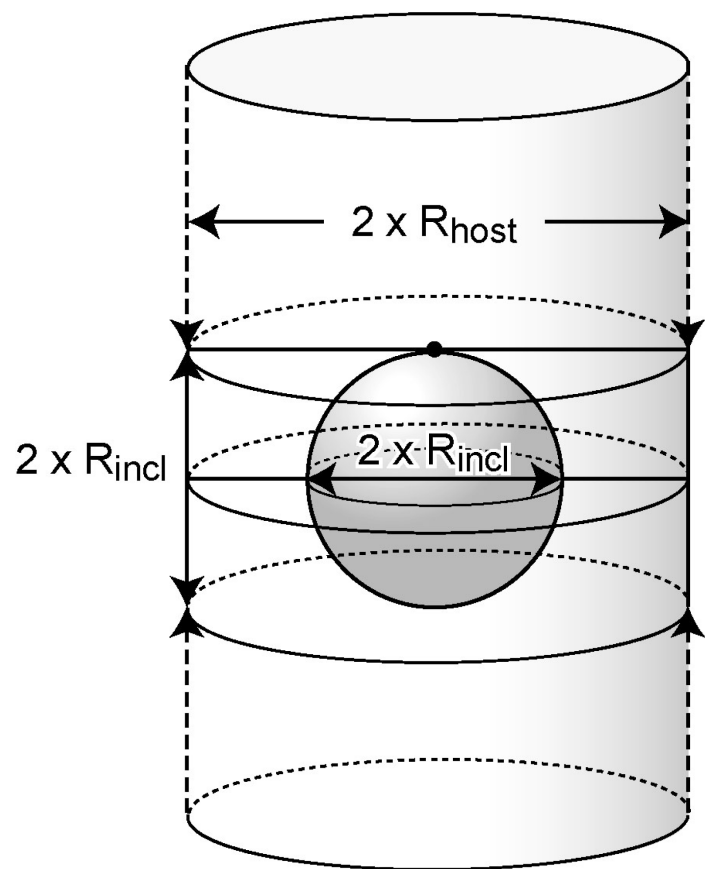

Figure 1. Simplified ablation geometry of a fluid inclusion (gas bubble) with radius $R_{\text {incl }}(\mu \mathrm{m})$ within the ablated host mineral (glass) idealized as a cylinder of radius $R_{\text {host }}$.

and therefore

$M_{\text {incl }}^{Y}=M_{\text {host }}^{X} S^{X / Y} k^{Y / X}$.

Let us now consider the following two equations, which relate mass and densities:

$M_{\text {incl }}=\rho_{\text {incl }} \times v_{\text {incl }}$

and

$M_{\text {host }}=\rho_{\text {host }} \times v_{\text {host }}$,

where $\rho_{\text {incl }}, \rho_{\text {host }}\left(\mathrm{g} \mathrm{cm}^{-3}\right)$ and $v_{\text {incl }}, v_{\text {host }}\left(\mathrm{cm}^{3}\right)$ are the densities and volumes of the inclusion and the host, respectively. If we define $C_{\text {incl }}^{Y}$ as the concentration (ppm) of element $Y$ in the inclusion, we can write

$C_{\mathrm{incl}}^{Y}=\frac{M_{\mathrm{incl}}^{Y}}{M_{\mathrm{incl}}}=\frac{M_{\mathrm{incl}}^{Y}}{p_{\mathrm{incl}} v_{\mathrm{incl}}}$.

It follows that

$C_{\text {incl }}^{Y}=\frac{M_{\text {incl }}^{Y}}{p_{\text {incl }} v_{\text {incl }}}$,

and

$C_{\text {host }}^{X}=\frac{M_{\text {host }}^{X}}{p_{\text {host }} v_{\text {host }}}$, 
with $C_{\text {host }}^{X}$ representing the concentration of element $X$ in the host mineral or host glass. Finally, if we write

$M_{\text {host }}^{X}=C_{\text {host }}^{X} \rho_{\text {host }} v_{\text {host }}$

and, substituting Eq. (8b) into Eq. (10b), find

$$
C_{\text {incl }}^{Y}=\frac{M_{\text {host }}^{X} S^{X / Y} k^{Y / X}}{p_{\text {incl }} v_{\text {incl }}}
$$

we can insert Eq. (11b) into Eq. (12) to obtain the final equation:

$$
C_{\text {incl }}^{Y}=\frac{C_{\text {host }}^{X} p_{\text {host }} v_{\text {host }} S^{X / Y} k^{Y / X}}{p_{\text {incl }} v_{\text {incl }}},
$$

which gives the concentration, in parts per million, of the unknown element $Y$ in the fluid inclusion or gas bubble as a function of the concentration, in parts per million, of a compatible element $(X)$ measured independently in the host mineral (glass), the densities $\left(\mathrm{g} \mathrm{cm}^{-3}\right)$ and volumes of the ablated inclusion and host $\left(\mu \mathrm{m}^{3}\right)$, a sensitivity factor, and the integrated laser ablation intensities (cps) for $Y$ in the inclusion (bubble) and for the known element $X$ in the host.

\subsection{Testing the new method based on a known quartz-hosted, metal-rich fluid inclusion}

To validate the new method, we have used a fluid inclusion that had been previously characterized by the traditional LAICP-MS method, using a femtosecond laser, by Vikentiev et al. (2012) (inclusion U294; Table 1) and have set out to quantify its trace $(\mathrm{Cu}, \mathrm{Ag}, \mathrm{Cd}, \mathrm{Au}, \mathrm{Pb}, \mathrm{Bi})$ and major $(\mathrm{Na})$ element concentrations using our procedure. This is a large fluid inclusion measuring $45 \mu \mathrm{m}$ in diameter, which contains a saline aqueous fluid. It is characterized by a homogenization temperature $T_{\mathrm{h}}$ equal to $245^{\circ} \mathrm{C}$ and a density $p_{\text {incl }}$ of $0.8 \mathrm{~g} \mathrm{~cm}^{-3}$. Its composition was originally obtained using the Na concentration derived independently by microthermometry as an internal standard ( $6 \mathrm{wt} \% \mathrm{NaCl}_{\text {equiv }}$ ). For the purpose of our test, $\mathrm{Si}$ was chosen as the highly compatible element in the quartz host, with an estimated concentration $\left(C_{\mathrm{host}}^{\mathrm{SiO} 2}\right)$ of $99.9 \mathrm{wt} \%$ (equal to $C_{\mathrm{host}}^{\mathrm{Si}}$ of $466978 \mathrm{ppm}$; Table 1). The inclusion radius ( $\left.R_{\text {incl }}\right)$ was measured at $22.5 \mu \mathrm{m}$. The average ablation crater radius $\left(R_{\text {host }}\right)$ was $24.5 \mu \mathrm{m}$, measured using a JEOL JSM-6360 LV scanning electron microscope (GET, Toulouse, France). In summary, calculations were conducted with an average $\left(R_{\text {host }}\right)$ radius of $24.5 \mu \mathrm{m}$. Considering simplified geometries of a sphere and a cylinder, respectively, for the ablated inclusion and the host quartz (Fig. 1), the volumes of the inclusion and the host quartz are $v_{\text {incl }}=4 / 3\left[\pi R_{\text {incl }}^{3}\right]$ and $v_{\text {host }}=4 / 3 \pi\left[\left(1.5 R_{\text {incl }}\right) R_{\text {host }}^{2}-R_{\text {incl }}^{3}\right]$, where $R_{\text {incl }}$ and $R_{\text {host }}$ are the radiuses of the inclusion and the ablated zone of the host mineral, respectively. Alternatively, the inclusion volume and radius may be measured by X-ray micro-tomography (Creon et al., 2018). We know that the femtosecond laser has no matrix effect between the external calibrator and the measured host mineral-fluid inclusion system (e.g., Velasquez et al., 2012; Poitrasson and d'Abzac, 2017; and references therein). Therefore, if we apply Eq. (13) using radii for volumes, we have

$$
C_{\text {incl }}^{Y}=\left[C_{\text {host }}^{X}\right]\left[\frac{p_{\text {host }}}{p_{\text {incl }}}\right]\left[\frac{1.5 R_{\text {host }}^{2}}{R_{\text {incl }}^{2}}-1\right]\left[S^{X / Y} k^{Y / X}\right] .
$$

In the equation, $S^{X / Y}$ is $\frac{S^{\mathrm{Si}}}{S^{\mathrm{Au}}}$, where $S^{\mathrm{Si}}$ and $S^{\mathrm{Au}}$ are chosen isotopic sensitivities $\left(\mathrm{cps} \mathrm{ppm}^{-1}\right)$ calculated for an external calibrator (NIST SRM 610; Table 1) for Si (as element $X$ ) and $\mathrm{Au}$ (as element $Y$ ). In Eq. (14), $k^{\mathrm{Au} / \mathrm{Si}}=\frac{\sum_{\mathrm{I}} \mathrm{Au}}{\sum_{\mathrm{I}} \mathrm{Si}}$, where $\sum_{\mathrm{I}} \mathrm{Au}$ and $\sum_{\mathrm{I}} \mathrm{Si}$ are the integrated (background-subtracted) LA-ICP-MS intensities (cps) for the elements $Y(\mathrm{Au})$ and $X$ $(\mathrm{Si})$, respectively, where $\sum_{\mathrm{I}} \mathrm{Au}$ was integrated in the fluid inclusion burst zone, while the integration for $\sum_{\mathrm{I}} \mathrm{Si}$ was shifted to the signal of quartz only (Fig. 2a). We performed several comparisons of critical major and trace element concentrations (e.g., $\mathrm{Na}, \mathrm{Au}$, etc.) calculated according to Eq. (14) with those obtained by the traditional method (Table 1, Supplement 1). The comparison suggests that the optimal period for integrating the $Y$ signal of the LA-ICP-MS pattern is $2.5 \mathrm{~s}$, corresponding to the signal related to the fluid ablation. Given a host quartz ablation rate of $0.42 \mu \mathrm{m}$ per pulse, or $2.1 \mu \mathrm{m} \mathrm{s}^{-1}$ with a repetition rate of $5 \mathrm{~Hz}$ (d'Abzac, 2010; Courtieu et al., 2011), the integrated period of $\sim 2.5 \mathrm{~s}$ corresponds to the integration of a $\sim 5 \mu \mathrm{m}$ quartz ablation pattern. Indeed, the integration period for element $Y$ should correspond to the peak(s) of the ablation pattern related to the introduction of the NaCl-bearing fluid from the ablated inclusion to the ICP-MS system. The calculated concentrations (based on Eqs. 13 and 14) are from $0.7 \%$ to $24 \%$ (exceptionally, $27 \%$ for $\mathrm{Bi}$ ) of the relative percentage difference (RPD) between major and trace element contents, obtained by the traditional method of LA-ICP-MS quantification. The values obtained for the major element $\mathrm{Na}$ and its corresponding $\mathrm{NaCl}_{\text {equiv }}$ concentration (5.1 wt \%; Table 1) are within the $15 \%$ RPD limit agreement with those estimated based on microthermometry ( $\left.6 \mathrm{wt} \% \mathrm{NaCl}_{\text {equiv }}\right)$.

Additionally, we have quantified a second fluid inclusion (019-E1, Borisova et al., 2012). This is a metal-rich, pegmatitic-quartz-hosted fluid inclusion measuring $50 \mu \mathrm{m}$ in average diameter, which contains crystalline salts and a saline aqueous fluid. It is characterized by a homogenization temperature $T_{\mathrm{h}}$ equal to $\sim 600^{\circ} \mathrm{C}$ and a density $p_{\text {incl }}$ of $1.2 \mathrm{~g} \mathrm{~cm}^{-3}$. Its composition was originally obtained using the $\mathrm{Na}$ concentration derived independently by microthermometry as an internal standard (34.4 wt $\% \mathrm{NaCl}_{\text {equiv }}$; Fig. 2b, Table 2, Supplement 2). We performed several comparisons of major and trace element concentrations (e.g., $\mathrm{Na}, \mathrm{K}, \mathrm{Rb}, \mathrm{Sr}$, $\mathrm{Mo}, \mathrm{Sn}, \mathrm{Ag}, \mathrm{Cs}, \mathrm{Pb}$ ) calculated according to Eq. (14) with those obtained by the traditional method (Table 2). The comparison suggests that the optimal period for integrating the $Y$ 


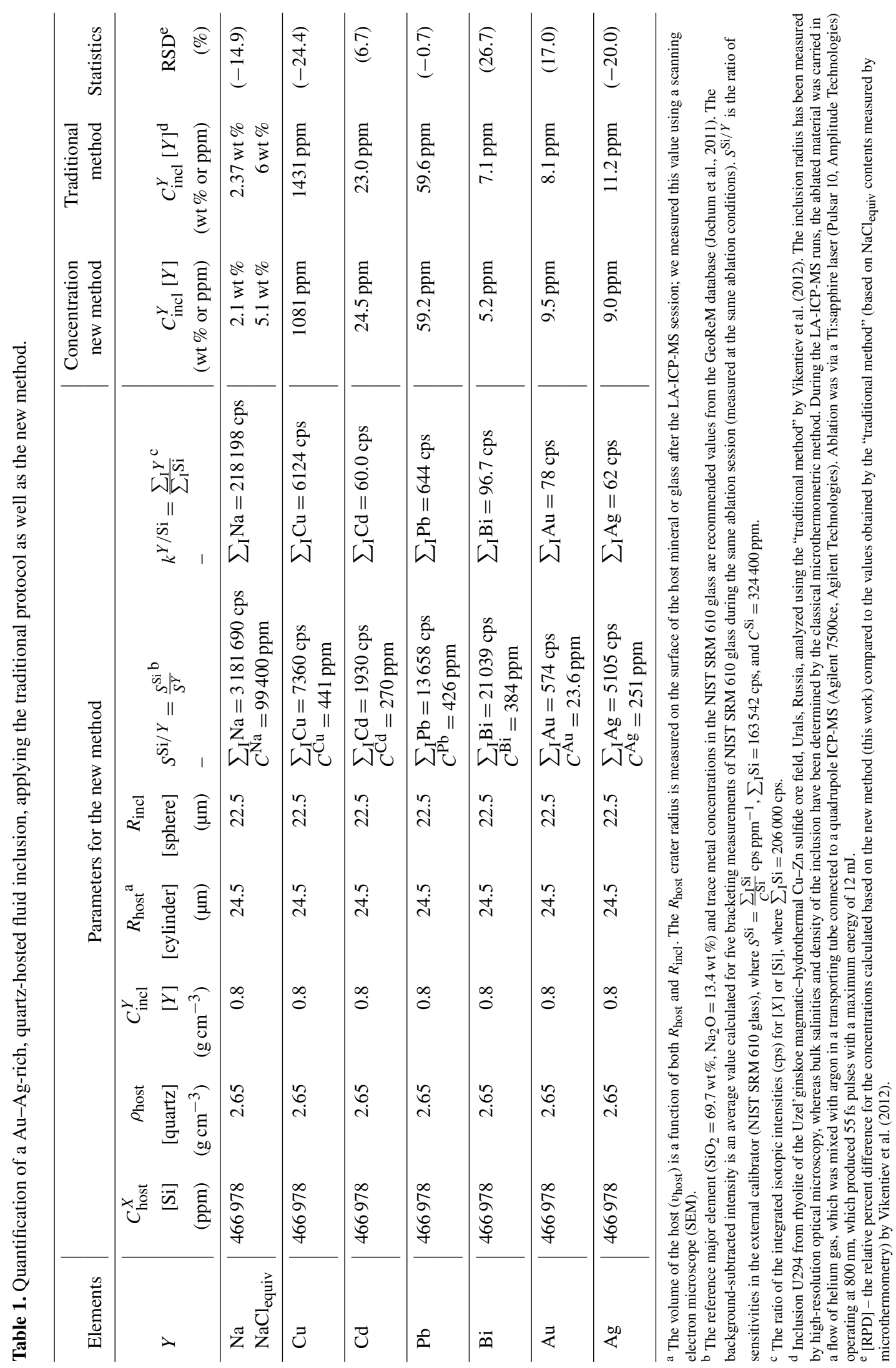


(a)

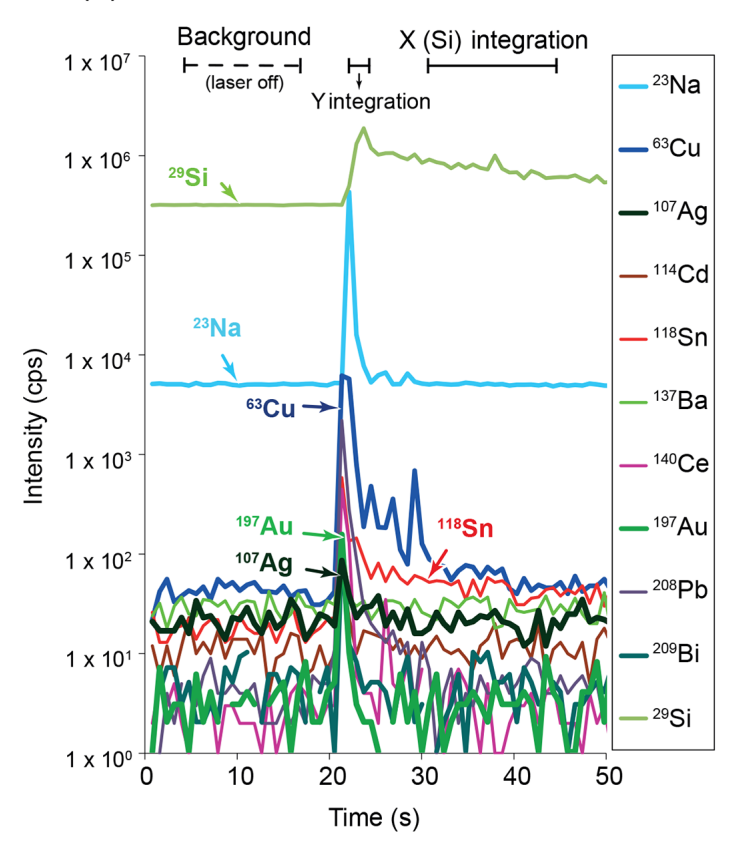

(b)

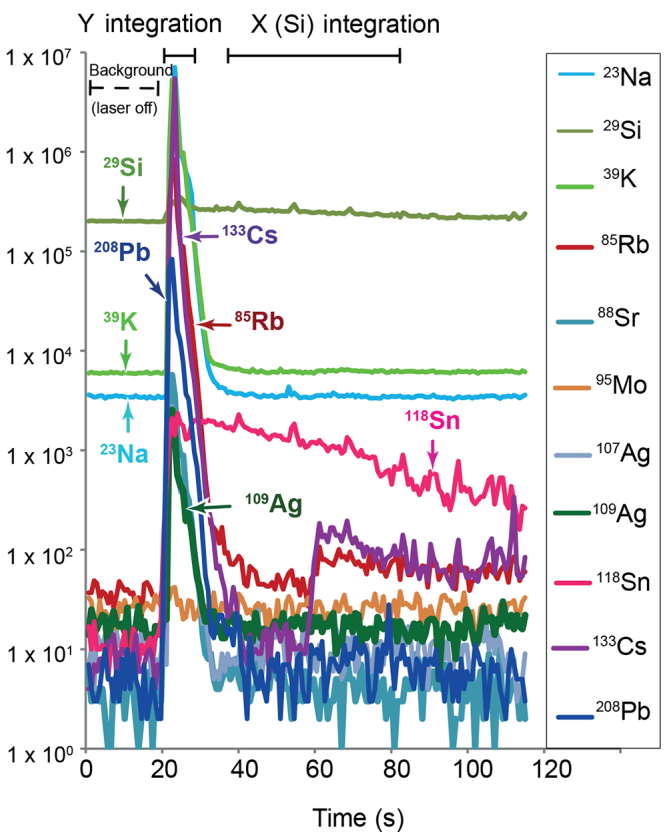

Figure 2. (a) Femtosecond LA-ICP-MS pattern of the ablation of a fluid inclusion hosted in natural quartz (Au-Ag-rich inclusion U294, courtesy of Ilya Vikentiev). Quantification by the traditional method gives $C_{\text {incl }}^{\mathrm{Au}}=8.1 \mathrm{ppm}$ and $C_{\text {incl }}^{\mathrm{Ag}}=11.2 \mathrm{ppm}$ (Vikentiev et al., 2012). Ablation was performed with a near-infrared femtosecond laser using a repetition rate of $5 \mathrm{~Hz}$ and an energy of $\sim 1 \mathrm{~mJ}$ per pulse; the ablation rate was $0.42 \mu \mathrm{m}$ per pulse or $2.1 \mu \mathrm{m} \mathrm{s}^{-1}$. Measurement of the $Y$ element is done by integrating the spectra obtained during bursting of the fluid inclusion, represented here by the $2.5 \mathrm{~s}$ peak interval marked by a " $Y$ integration" line ( $Y$ elements considered here are $\mathrm{Na}, \mathrm{Cu}, \mathrm{Ag}$, $\mathrm{Cd}, \mathrm{Au}, \mathrm{Pb}, \mathrm{Bi}$ ). The flat pattern right after the inclusion peak is taken to represent ablation of the host mineral (here quartz) for $30 \mathrm{~s}$, so the integration for the $X$ element (here $\mathrm{Si}$ ) is shifted to this interval (" $X$ (Si) integration") line. (b) Femtosecond LA-ICP-MS pattern of the ablation of a fluid inclusion hosted in natural quartz (pegmatite inclusion 019-E1, courtesy of Rainer Thomas). For example, quantification by the traditional method gives $C_{\text {incl }}^{\mathrm{Cs}}=22700 \mathrm{ppm}$ (Borisova et al., 2012). Ablation was performed with a near-infrared femtosecond laser using a repetition rate of $5 \mathrm{~Hz}$ and an energy of $\sim 1 \mathrm{~mJ}$ per pulse; the ablation rate was $0.42 \mu \mathrm{m}$ per pulse or $2.1 \mu \mathrm{m} \mathrm{s}^{-1}$. Measurement of the $Y$ element is done by integrating the spectra obtained during bursting of the fluid inclusion, represented here by the $6.1 \mathrm{~s}$ peak interval marked by a " $Y$ integration" line ( $Y$ elements considered here are $\mathrm{Na}, \mathrm{K}, \mathrm{Rb}, \mathrm{Sr}, \mathrm{Mo}, \mathrm{Sn}, \mathrm{Ag}, \mathrm{Cs}, \mathrm{Pb}$ ). The flat pattern right after the inclusion peak is taken to represent ablation of the host mineral (here quartz) for $30 \mathrm{~s}$, so the integration for the $X$ element (here $\mathrm{Si}$ ) is shifted to this interval (" $X(\mathrm{Si})$ integration") line.

signal of the LA-ICP-MS pattern is $6.1 \mathrm{~s}$, corresponding to the signal related to the fluid inclusion ablation. The fluid is evacuated more rapidly from an inclusion just after its opening compared to the ablated host; the LA-ICP-MS signals of the fluid and the host are decoupled (there is a small shift in the signal). Indeed, the integration period for element $Y$ should correspond to the strongest peak(s) of the ablation pattern related to the introduction of the NaCl-bearing fluid from the ablated inclusion to the ICP-MS system. The calculated concentrations (based on Eqs. 13 and 14) are from $2.2 \%$ to $14.5 \%$ of the relative percentage difference (RPD) between major and trace element contents, obtained by the traditional method of LA-ICP-MS quantification. The values obtained for the major element $\mathrm{Na}$ and its corresponding $\mathrm{NaCl}_{\text {equiv }}$ concentrations ( $30.9 \mathrm{wt} \%$; Table 1 ) are within the $10 \%$ RPD limit, which is in good agreement with those estimated based on microthermometry ( $34.4 \mathrm{wt} \% \mathrm{NaCl}_{\text {equiv }}$ ).
The application of Eqs. (13) and (14) for the calculations of major and trace element concentrations in the $\mathrm{CO}_{2}-$ and $\mathrm{CO}$-rich inclusions requires determination of the $\mathrm{C}-\mathrm{O}-\mathrm{H}$ fluid density. This may be performed based on micro-Raman spectroscopy (e.g., Borisova et al., 2014) or theoretically if the proportions of the gas components are well determined or known (e.g., Kokh et al., 2016, and references therein).

\subsection{An additional test for the quantification method}

The correctness of the integrated period of the laser ablation pattern $\left(\sum_{\mathrm{I}} Y\right)$ may be verified by considering two instead of one known (major, minor or trace) element concentrations in the host mineral or glass $\left(C_{\mathrm{host}}^{X}\right.$ and $\left.C_{\mathrm{host}}^{W}\right)$. Therefore, the test requires measuring the intensities of four isotopes $(X$, $Y, W, Z$ ) during the ablation. Elements $X$ and $W$, compatible with the host quartz or silicate glass (quenched silicate melt), may be non-volatile elements like $\mathrm{Ti}, \mathrm{Al}, \mathrm{Mg}$ and $\mathrm{Cr}$ 


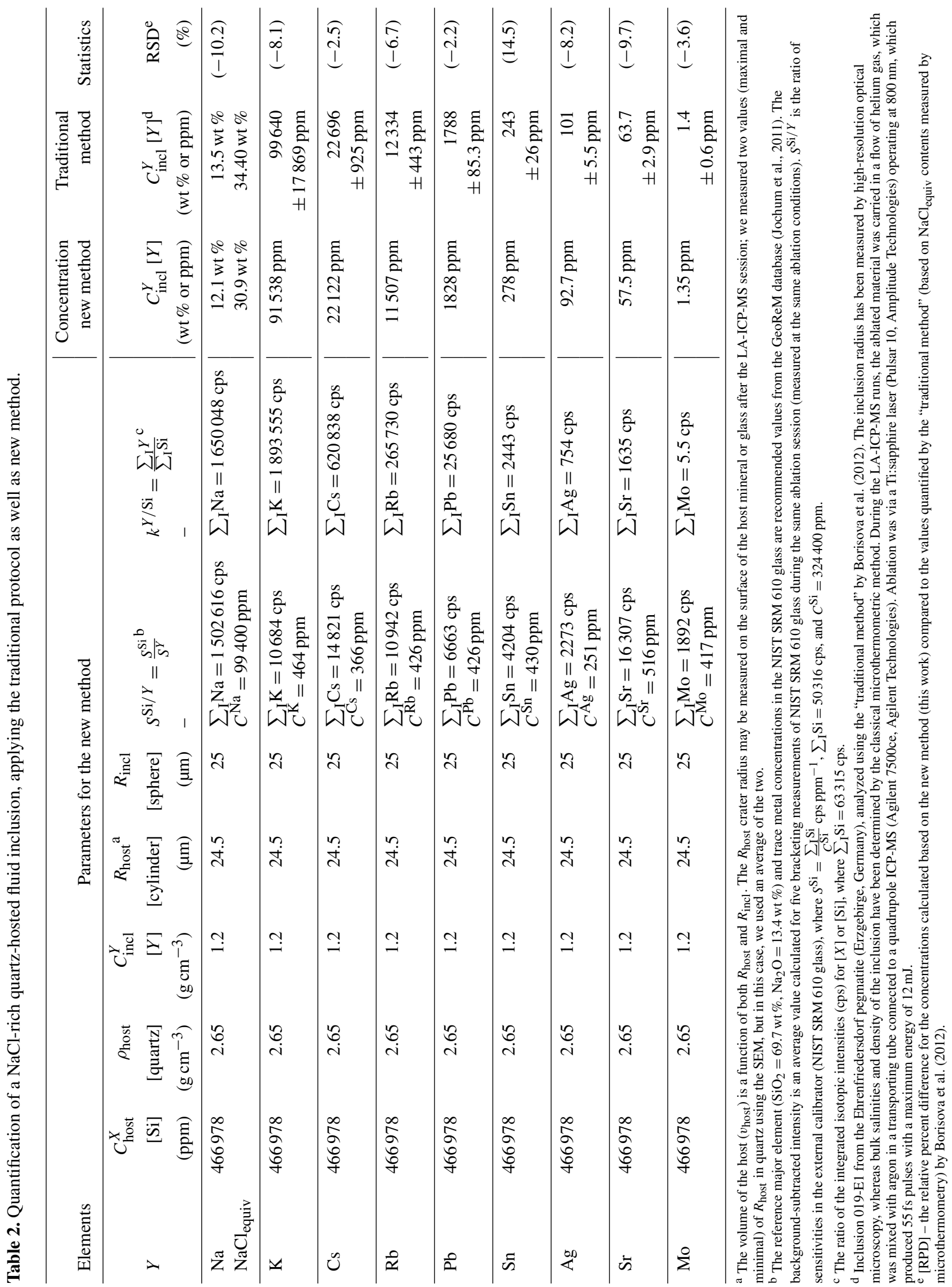


(or moderately volatile $\mathrm{Si}$ ), which are easily quantifiable by microanalytical techniques (e.g., electron probe microanalysis (EPMA), LA-ICP-MS method). Two equations for $C_{\text {host }}^{X}$ and $C_{\text {host }}^{W}$ are thus combined to form the following equation:

$\frac{C_{\text {incl }}^{Y}}{C_{\text {incl }}^{Z}}=\frac{C_{\text {host }}^{X} S^{X / Y} k^{Y / X}}{C_{\text {host }}^{W} S^{W / Z} k^{Z / W}}$,

where, respectively, $C_{\text {incl }}^{Y}$ and $C_{\text {incl }}^{Z}$ are the calculated concentrations of incompatible elements $Y$ and $Z(\mathrm{ppm})$ in the fluid inclusion (gas bubble) based on Eq. (13); $C_{\text {host }}^{X}$ and $C_{\text {host }}^{W}$ are the known concentrations of compatible elements $X$ and $W(\mathrm{ppm})$ in the host mineral; $S^{X / Y}=\frac{S^{X}}{S^{Y}}$ and $S^{W / Z}=\frac{S^{W}}{S^{Z}}$ are ratios of sensitivities (cps ppm $\left.{ }^{-1}\right)$ in an external calibrator (reference silicate glass) measured at the same conditions as those applied for the fluid analysis; and $k^{Y / X}$ and $k^{Z / W}$ are coefficients relating ratios of the integrated intensities after background subtraction (cps). The $k^{Y / X}$ is equal to $\frac{\sum_{\mathrm{I}} Y}{\sum_{\mathrm{I}} X}$, and $k^{Z / W}$ is equal to $\frac{\sum_{\mathrm{I}} Z}{\sum_{\mathrm{I}} W}$ for the selected isotopes in the ablated zone of the host mineral-fluid inclusion (host glassbubble) system. Thus, the concentration ratios for two incompatible elements $C_{\text {incl }}^{Y}$ and $C_{\text {incl }}^{Z}$ as well as the integration period $\Delta \mathrm{t}$, which determines the values of the isotopic intensities $\sum I(\Delta t)\left(\sum_{\mathrm{I}} X, \sum_{\mathrm{I}} Y, \sum_{\mathrm{I}} Z, \sum_{\mathrm{I}} W\right.$ for the selected isotopes of elements $\mathrm{X}, \mathrm{Y}, \mathrm{Z}, \mathrm{W}$; cps), may be precisely evaluated based on the known concentrations of two (major or minor) elements $\left(C_{\text {host }}^{X}\right.$ and $C_{\text {host }}^{W}$ ) which are compatible with the host mineral (host glass). This test may be applied to and is highly recommended for the glass-hosted fluid bubbles.

\section{Conclusions}

We have developed a new method for standardless quantification of element concentrations (at parts-per-million to weight percent levels) in natural and synthetic fluid inclusions and gas bubbles by femtosecond LA-ICP-MS analysis using only an external calibrator. As an example, the new method may be applied to estimate the major and trace element (metal and metalloid) concentrations in hydrous carbonic $(\mathrm{C}-\mathrm{O}-\mathrm{H}$ such as $\mathrm{CO}$ - or $\mathrm{CO}_{2}$-rich etc.) fluid inclusions and bubbles, with uncertainties mostly better than $25 \%$ (the uncertainties for Bi reach $27 \%$ ). The new method requires precise quantification of the fluid density, the inclusion or bubble volume or average radius, and measurement of the laser ablation crater radius by independent microanalytical techniques. By means of independently obtained concentration data for two elements in the host mineral (glass), it is possible to verify the quantification of the fluid composition. Because femtosecond lasers greatly reduce matrix effects compared to classical nanosecond lasers, ICP-MS coupled to femtosecond lasers offers new perspectives for standardless quantification of fluid inclusions, gas bubbles and potentially $\mathrm{C}-$ H-rich (organic) matrices. This method may be tested with modern ultraviolet nanosecond (e.g., excimer type) lasers, which have been demonstrated to have moderate matrix effects between aqueous fluids, oxides, (possibly sulfides) and silicates. This method is provided as a user-friendly Excel spreadsheet, available as Table S1 in the Supplement.

Code and data availability. The calculations are given in the Supplement 1 and Supplement 2. The table for the numerical calculations and an external use is given as Table $\mathrm{S} 1$.

Supplement. The supplement related to this article is available online at: https://doi.org/10.5194/ejm-33-305-2021-supplement.

Author contributions. All authors participated in the manuscript preparation for publication.

Competing interests. The authors declare that they have no conflict of interest.

Acknowledgements. We thank European Journal of Mineralogy editors Elisabetta Rampone and Klaus Mezger as well as the two anonymous reviewers for valuable suggestions and comments that helped improve the initial manuscript. The authors are grateful to C. Hester for drafting Fig. 1. We wish to thank Ilya Vikentiev and Rainer Thomas for valuable discussions and for providing the metal-rich fluid inclusions for testing our method.

Financial support. This research was supported by ANR-2011Blanc SIMI 5-5 009 "Rôle du soufre dans le devenir des métaux d'intérêt économique dans les fluides géologiques" and by the INSU 2015-CESSUR grant "Fluid inclusion characterization in peralkaline rare-metal deposits: implications for mobility of immobile elements".

Review statement. This paper was edited by Klaus Mezger and reviewed by two anonymous referees.

\section{References}

Borisova, A. Y., Pichavant, M., Polvé, M., Wiedenbeck, M., Freydier, R., and Candaudap, F.: Trace element geochemistry of the 1991 Mt. Pinatubo silicic melts, Philippines: Implications for ore-forming potential of adakitic magmatism, Geochim. Cosmochim. Ac., 70, 3702-3716, https://doi.org/10.1016/j.gca.2006.04.030, 2006.

Borisova, A. Y., Freydier, R., Polvé, M., Salvi, S., Candaudap, F., and Aigouy, T.: In situ multi-elemental analysis of the Mount Pinatubo quartz-hosted melt inclusions by NIR femtosecond laser ablation - inductively coupled plasma - 
mass spectrometry, Geostand. Geoanal. Res., 32, 209-229, https://doi.org/10.1111/j.1751-908X.2008.00882.x, 2008.

Borisova, A. Y., Thomas, R., Salvi, S., Candaudap, F., Lanzanova, A., and Chmeleff, J.: Tin and associated metal and metaloid geochemistry by femtosecond LA-ICP-MS microanalysis in pegmatite-leucogranite melt and fluid inclusions: New evidence for melt-melt-fluid immiscibility, Mineral. Mag., 76, 91-113, https://doi.org/10.1180/minmag.2012.076.1.91, 2012.

Borisova, A. Y., Toutain, J. P., Dubessy, J. Pallister J., Zwick, A., and Salvi, S.: $\mathrm{H}_{2} \mathrm{O}-\mathrm{CO}_{2}-\mathrm{S}$ fluid triggering the 1991 Mount Pinatubo climactic eruption (Philippines), Bull. Volcanol., 76, 800, https://doi.org/10.1007/s00445-014-0800-3, 2014.

Cauzid, J., Philippot, P., Somogyi, A., Ménez, B., Simionovici, A., and Bleuet, P.: Standardless quantification of single fluid inclusions using synchrotron radiation induced X-ray fluorescence, Chem. Geol., 227, 165-183, https://doi.org/10.1016/j.chemgeo.2005.09.012, 2006.

Courtieu, C., d'Abzac, F.-X., Chmeleff, J., Guillaume, D., and Seydoux-Guillaume, A.-M.: Performance of $800 \mathrm{~nm}$ femtosecond laser ablation on natural and synthetic quartz, Eur. J. Mineral., 23, 391-400, https://doi.org/10.1127/09351221/2011/0023-2113, 2011.

Creon, L., Levresse, G., Remusat, L., Bureau, H., and CarrascoNúñez, G.: New method for silicate melt inclusion homogenization: A mathematical approach coupling X-ray microtomography, geochemistry and thermodynamics, Chem. Geol., 483, 162173, https://doi.org/10.1016/j.chemgeo.2018.02.038, 2018.

d'Abzac, F.-X.: Effets d'une impulsion laser Infra-Rouge femtoseconde sur les micro-nanostructures des minéraux, Implications pour les analyses in-situ par LA-ICP-MS, Thèses de Doctorat, Université Toulouse III, Toulouse, France, 242 pp., 2010.

Fernandez, B., Claverie, F., Pécheyran, C., and Donard, O. F. X.: Direct analysis of solid samples by fs-LA-ICP-MS, Trend. Anal. Chem., 26, 951-966, https://doi.org/10.1016/j.trac.2007.08.008, 2007.

Ferrando, S., Frezzotti, M. L., Petrelli, M., and Compagnoni, R.: Metasomatism of continental crust during subduction: the UHP whiteschists from the Southern Dora-Maira Massif (Italian Western Alps), J. Metamorph. Geol., 27, 739-756, https://doi.org/10.1111/j.1525-1314.2009.00837.x, 2009.

Halter, W. E., Pettke, T., Heinrich, C. A., and Rothen-Rutishauser, B.: Major to trace element analysis of melt inclusions by laserablation ICP-MS: method of quantification, Chem. Geol., 183, 63-86, https://doi.org/10.1016/S0009-2541(01)00372-2, 2002.

Hanley, J. J. and Gladney, E. R.: The presence of carbonicdominant volatiles during the crystallization of sulfidebearing mafic pegmatites in the North Roby Zone, Lac des Iles Complex, Ontario, Econom. Geol., 106, 33-54, https://doi.org/10.2113/econgeo.106.1.33, 2011.

Heinrich, C. A., Pettke, T., Halter, W. E., Aigner-Torres, M., Günther, D., Hattendorf, B., Bleiner, D., Guillong, M., and Horn, I.: Quantitative multi-element analysis of minerals, fluid and melt inclusions by laser-ablation inductively-coupled-plasma mass-spectrometry, Geochim. Cosmochim. Ac., 67, 3473-3496, https://doi.org/10.1016/S0016-7037(03)00084-X, 2003.

Horn, I., Guillong, M., and Günther, D.: Wavelength dependant ablation rates for metals and silicate glasses using homogenized laser beam profiles - implications for LA-ICP-MS,
Appl. Surf. Sci., 182, 91-102, https://doi.org/10.1016/S01694332(01)00465-2, 2001.

Jochum, K. P., Weis, U., Stoll, B., Kuzmin, D., Yang, Q., Raczek, I., Jacob, D. E., Stracke, A., Birbaum, K., Frick, D. A., Günther, D., and Enzweiler, J.: Determination of Reference Values for NIST SRM 610-617 Glasses Following ISO Guidelines, Geostand. Geoanal. Res., 35, 397-429, https://doi.org/10.1111/j.1751908X.2011.00120.x, 2011.

Kamenetsky, V. S. and Kamenetsky, M. B.: Magmatic fluids immiscible with silicate melts: examples from inclusions in phenocrysts and glasses, and implications for magma evolution and metal transport, Geofluids, 10, 293-211, https://doi.org/10.1111/j.1468-8123.2009.00272.x, 2010.

Kamenetsky, V. S., Davidson, P., Mernagh, T. P., Crawford, A. J., Gemmell, J. B., Portnyagin, M. V., and Shinjo, R.: Fluid bubbles in melt inclusions and pillow-rim glasses: high-temperature precursors to hydrothermal fluids?, Chem. Geol., 183, 349-364, https://doi.org/10.1016/S0009-2541(01)00383-7, 2002.

Kokh, M. A., Lopez, M., Gisquet, P., Lanzanova, A., Candaudap, F., Besson, P., and Pokrovski G. S.: Combined effect of carbon dioxide and sulfur on vapor-liquid partitioning of metals in hydrothermal systems, Geochim. Cosmochim. Ac., 187, 311-333, https://doi.org/10.1016/j.gca.2016.05.010, 2016.

Leach, A. M. and Hieftje G. M.: Standardless semiquantitative analysis of metals using single-shot laser ablation inductively coupled plasma time-of-flight mass spectrometry, Anal. Chem., 73, 2959-2967, https://doi.org/10.1021/ac001272n, 2001.

Longerich, H. P., Jackson, S. E., and Günther, D.: Laser ablation inductively coupled plasma mass-spectrometric transient signal data acquisition and analyte concentration calculation, J. Anal. Atom. Spectrom., 11, 899-904, https://doi.org/10.1039/JA9961100899, 1996.

Lowenstern, J. B.: Bursting the bubble of melt inclusions, Am. Mineral., 100, 672-673, https://doi.org/10.2138/am-2015-5254, 2015.

Pettke, T., Oberli, F., Audétat, A., Guillong, M., Simon, A. C., Hanley, J. J., and Klemm, L. M.: Recent developments in element concentration and isotope ratio analysis of individual fluid inclusions by laser ablation single and multiple collector ICP-MS, Ore Geol. Rev., 44, 10-38, https://doi.org/10.1016/j.oregeorev.2011.11.001, 2012.

Poitrasson, F. and d'Abzac, F.-X.: Femtosecond laser ablation inductively coupled plasma source mass spectrometry for elemental and isotopic analysis: are ultrafast lasers worthwhile?, J. Anal. Atom. Spectrom., 32, 1075-1091, https://doi.org/10.1039/C7JA00084G, 2017.

Rickers, K., Thomas, R., and Heinrich, W.: Trace-element analysis of individual synthetic and natural fluid inclusions with synchrotron radiation XRF using Monte Carlo simulation for quantification, Eur. J. Mineral., 16, 23-35, https://doi.org/10.1127/0935-1221/2004/0016-0023, 2004.

Scambelluri, M., Müntener, O., Ottolini, L., Pettke, T. T., and Vannucci, $\mathrm{R} .:$ The fate of $\mathrm{B}, \mathrm{Cl}$, and $\mathrm{Li}$ in the subducted oceanic mantle and in the antigorite breakdown fluids, Earth Planet. Sc. Lett., 222, 217-234, https://doi.org/10.1016/j.epsl.2004.02.012, 2004.

Schafer, B., Frischknecht, R., Günther, D., and Dingwell, D. B.: Determination of trace-element partitioning between fluid and melt using LA-ICP-MS analysis of synthetic 
fluid inclusions in glass, Eur. J. Mineral., 11, 415-426, https://doi.org/10.1127/ejm/11/3/0415, 1999.

Schiavi, F., Bolfan-Casanova, N., Buso, R., Laumonier, M., Laporte, D., Medjoubi, K., Venugopal, S., Gomez-Ulla, A., Cluzel, N., and Hardiagon, M.: Quantifying magmatic volatiles by Raman microtomography of glass inclusion-hosted bubbles, Geochem. Persp. Let., 16, 17-24, https://doi.org/10.7185/geochemlet.2038, 2020.

Seo, J. H., Guillong, M., Aerts, M., Zajacz, Z., and Heinrich, C. A.: Microanalysis of $\mathrm{S}, \mathrm{Cl}$ and $\mathrm{Br}$ in fluid inclusions by LA-ICP-MS, Chem. Geol., 284, 35-44, https://doi.org/10.1016/j.chemgeo.2011.02.003, 2011.

Simakin, A. G., Salova, T. P., Gabitov, R. I., and Isaenko, S. I.: Dry $\mathrm{CO}_{2}-\mathrm{CO}$ fluid as an important potential deep Earth solvent, Geofluids, 16, 1043-1057, https://doi.org/10.1111/gfl.12204, 2016.

Simakin, A., Salova, T., Borisova, A. Y., Pokrovski, G. S., Shaposhnikova, O., Tyutyunnik, O., Bondarenko, G., Nekrasov, A., and Isaenko, S. I.: Experimental study of Pt solubility in the $\mathrm{CO}-\mathrm{CO}_{2}$ fluid at low $f_{\mathrm{O}_{2}}$ and subsolidus conditions of the ultramafic-mafic intrusions, Minerals, 11, 225, https://doi.org/10.3390/min11020225, 2021.
Spandler, C., Mavrogenes, J., and Hermann, J.: Experimental constraints on element mobility from subducted sediments using high-P synthetic fluid/melt inclusions, Chem. Geol., 239, 228249, https://doi.org/10.1016/j.chemgeo.2006.10.005, 2007.

Velasquez, G., Borisova, A. Y., Salvi, S., and Beziat, D.: In situ $\mathrm{Au}$ and $\mathrm{Cu}$ microanalysis in natural pyrite by nearinfrared femtosecond laser ablation (fs-LA) inductively coupled plasma quadrupole mass spectrometry (ICP-QMS): No evidence for matrix effect, Geostand. Geoanal. Res., 36, 315-324, https://doi.org/10.1111/j.1751-908X.2012.00152.x, 2012.

Velasquez, G., Borisova, A. Y., Baron, S., and Robbiola, L.: In situ analysis of copper alloys by femtosecond laser ablation inductively coupled plasma mass spectrometry: Constrains on matrix effects, Am. J. Anal. Chem., 9, 150-161, https://doi.org/10.4236/ajac.2018.93013, 2018.

Vikentiev, I. V., Borisova, A. Y., Karpukhina, V. S., Naumov, V. B., and Ryabchikov, I. D.: Direct data on the ore potential of acid magmas of the Uzel'ginskoe ore field (Southern Urals, Russia), Dokl. Earth Sci., 443, 401-405, https://doi.org/10.1134/S1028334X12030300, 2012. 